\title{
When in Trouble Think of the Bubble: Paradoxical Cerebral Arterial Gas Embolism after Endoscopic Retrograde Cholangiopancreatography
}

\author{
Konstantinos Ekmektzoglou ${ }^{a, b} \quad$ Georgios Alexandrakis ${ }^{b}$ \\ Konstantinos Dimopoulos ${ }^{b}$ Panagiotis Tsibouris $^{b}$ \\ Chrysostomos Kalantzis $^{b}$ Erasmia Vlachou $^{b}$ Periklis Apostolopoulos ${ }^{b}$ \\ aSchool of Medicine, European University Cyprus, Nicosia, Cyprus; ${ }^{b}$ Department of \\ Gastroenterology, Army Share Fund Hospital, Athens, Greece
}

\section{Keywords}

Endoscopic retrograde cholangiopancreatography - Air emboli · Case report - Diagnosis .

Treatment

\begin{abstract}
Air embolism (a result of direct communication with the vasculature and an external pressure gradient from the gastrointestinal or the biliary tract), although rare, is a potentially devastating adverse event seen in endoscopic retrograde cholangiopancreatography (ERCP) procedures. Whether venous, arterial, or paradoxical, the clinical presentation ranges from asymptomatic patients to cardiorespiratory arrest. This is of particular importance because it makes the diagnosis of air embolism even more difficult in an already sedated patient. Since early recognition increases the chances of patients' survival, endoscopists should be highly motivated and trained to recognize this complication as early as possible. With only 60 cases of air embolism reported (and even fewer related to paradoxical air embolism), we aimed to report a case of
\end{abstract}

\begin{tabular}{ll}
\hline & Konstantinos Ekmektzoglou \\
School of Medicine, European University Cyprus \\
6 Diogenous Street, 2404 Engomi, Nicosia, P.O. Box 22006 \\
CY-1516 Nicosia (Cyprus) \\
ekmektzo@hotmail.com
\end{tabular}




\section{Case Reports in Gastroenterology}

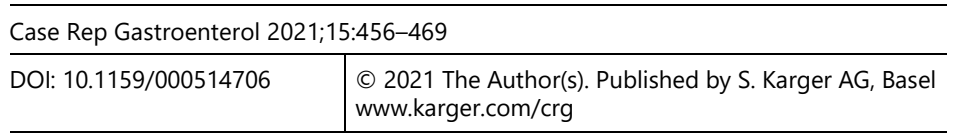

Ekmektzoglou et al.: Paradoxical Air Embolism after ERCP

paradoxical cerebral air embolism in a patient undergoing ERCP due to a common bile duct stricture and to provide a mini-review of this clinical entity that can serve as a bedside quick reference guide for endoscopists worldwide.

(C) 2021 The Author(s)

Published by S. Karger AG, Basel

\section{Introduction}

Endoscopic retrograde cholangiopancreatography (ERCP) has become the gold standard when treating patients with benign or malignant diseases of the biliary tract [1]. However, any ERCP (as well as all endoscopic procedures) is not without adverse effects. While post-ERCP pancreatitis, bleeding, perforation, and infectious adverse events are amongst the most common, cardiopulmonary adverse events should not be considered negligible, accounting for 4$16 \%$ of ERCP-related adverse events. Amongst the latter, air embolism, although rare, is a potentially devastating adverse event $[2,3]$.

Air embolism can take the form of venous air embolism (where the embolus reaches the pulmonary circulation), systemic arterial air embolism (where the embolus reaches the coronary or the cerebral arteries), and paradoxical air embolism (where the venous embolus reaches the systemic circulation). A recent prospective cohort study over a 15-month period of patients who underwent ERCP monitored for venous arterial embolism reported an incidence of $2.4 \%$ (20 out of 843 ERCP procedures) [4]. The United Stated of America National Inpatient Sample from 1998 to 2013 reported the occurrence of air embolism in 3.32 per 100,000 ERCP procedures [5]. With only 60 cases of air embolism reported (and even fewer related to paradoxical air embolism) [6-58], we aimed to report a case of paradoxical cerebral air embolism in a patient undergoing ERCP due to a common bile duct (CBD) stricture and to provide a mini-review of this clinical entity that can serve as a bedside quick reference guide for endoscopists worldwide.

\section{Case Presentation}

A 79-year-old male was admitted to our department for a programmed ERCP session for a mid-CBD stricture. His past medical history included hypertension and type 2 diabetes mellitus. He was given $8 \mathrm{mg}$ midazolam premedication as well as $50 \mathrm{mg}$ pethidine (both intravenously). The patient was placed in a left lateral decubitus position while receiving oxygen $\left(\mathrm{O}_{2}\right)$ through a nasal cannula. Monitoring included noninvasive arterial blood pressure monitoring by cuff, pulse oximetry, and three-lead electrocardiography. End-tidal carbon dioxide $\left(\mathrm{EtCO}_{2}\right)$ monitoring was not used because the patient was not breathing through a mask, endotracheal tube, or laryngeal mask airway, and an $\mathrm{EtCO}_{2}$ sampling nasal cannula was not available.

We reported the following ERCP findings: after CBD cannulation, contrast material was injected with the cholangiography revealing a 10-mm mid-CBD stricture with concomitant intrahepatic duct and suprapapillary dilation up to $17 \mathrm{~mm}$; no filling defect was noted (Fig. 1). An endoscopic sphincterotomy was performed using a wire-guided pull-type sphincterotome.

\section{Karger'=}




\section{Case Reports in Gastroenterology}

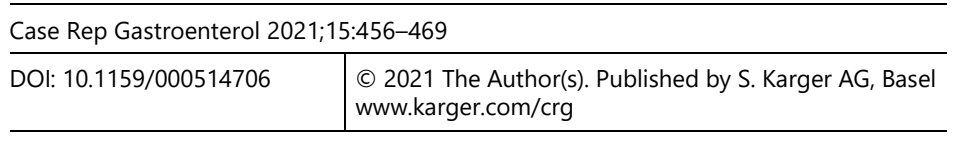

Ekmektzoglou et al.: Paradoxical Air Embolism after ERCP

Afterwards, a balloon catheter was inserted in the CBD via the wire-guided technique and inflated according to the CBD diameter. Under strict fluoroscopic guidance, the inflated balloon catheter was pulled several times from the CBD into the lumen of the duodenum; no stones were expelled. Balloon occlusion cholangiography at the end did not reveal any additional radiographic findings. Brushing of the stenotic CBD part was performed and a $10-\mathrm{Fr}, 7-\mathrm{cm}$ plastic stent was inserted into the CBD so as to secure bile drainage.

Up to that point, the procedure duration was $30 \mathrm{~min}$, during which the patient's vital signs and hemodynamic parameters were unremarkable. Due to the suprapapillary concomitant dilation noted before, we decided to terminate the ERCP by taking biopsy samples from the papilla; afterwards, the endoscope was withdrawn. While repositioning the patient from the left lateral decubitus to the supine position, he developed marked desaturation and hypotension. Flumazenil and naloxone were administered so as to reverse any remaining benzodiazepine and opioid effect, respectively, and high-flow $\mathrm{O}_{2}$ was also administered. Shortly after, the patient's hemodynamic parameters were restored, but he failed to regain consciousness (Glasgow Coma Scale score 7).

The patient was intubated within the following minutes and transported to the intensive care unit for further management. A bedside transesophageal echocardiogram bubble study was undertaken that demonstrated a patent foramen ovale (Fig. 2a, b). An emergency head computed tomography followed revealing no air but an extensive hypodense lesion in the right parieto-occipital lobe, indicating an extensive ischemic infarction (Fig. 3).

After a few days, the patient slowly regained consciousness and was extubated. However, he exhibited left hemiparesis. In that context, in our department we have been using $\mathrm{EtCO}_{2}$ monitoring ever since in all ERCP procedures.

\section{Discussion}

\section{Pathophysiology and Risk Factors}

Since air embolism is the end result of the direct communication between a source of air and the arterial or venous vasculature, its pathophysiology is twofold. On the one hand, an increased pressure gradient (insufflated air during any endoscopic procedure) must be present so as to favor the passage of air into the circulation. On the other hand, a disruption of a mucosal-vascular barrier (a direct vasculature defect per se or an organ wall defect) is also implicated [59-62].

During ERCP, the endoscopist controls the intermittent flow of pressurized air (or carbon dioxide $\left[\mathrm{CO}_{2}\right]$ ) so as to distend the bowel, the biliary tree, and the pancreatic duct. Both air amount and velocity play a crucial part in the severity of the embolus. However, in most cases this is not enough; for the air embolus to reach the regional veins or the arterial bed, a disruption of a mucosal-vascular barrier must take place. These disruptions may involve (1) endoscope (or its accessories)-induced mechanical irritation of the bile duct wall, (2) biliaryvenous fistulas, (3) air transgression into adjacent veins from mucosal and/or muscular wall inflammation, (4) intramural dissection of air into the portal venous system via injured duodenal vein radicles, (5) portal vein cannulation, and (6) portocaval or transhepatic collaterals

\section{Karger'=}




\section{Case Reports in Gastroenterology}

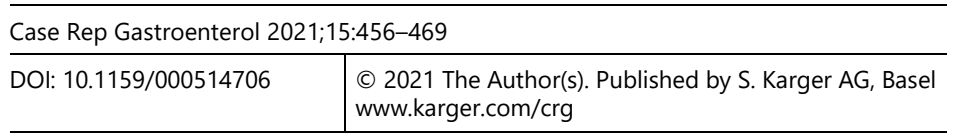

Ekmektzoglou et al.: Paradoxical Air Embolism after ERCP

[59-62]. Table 1 depicts the risk factors for developing air embolism (not only for ERCP patients).

\section{Semiology}

The effect and the corresponding sign(s) of an air bubble depend on both the flow and the volume of air introduced into the circulation. Therefore, the clinical presentation ranges from asymptomatic patients to cardiac arrest, with many cases only being diagnosed postmortem or due to the endoscopist's high clinical suspicion that triggers the undertaking of special diagnostic procedures [59-62].

What is characteristic regarding ERCP-related air embolism is that, most often, the symptoms appear or get significantly worse upon repositioning the patient from the prone to the supine position after the procedure has ended. The small hydrostatic gradient created between the pancreatic/biliary ducts and the draining veins in the prone or semiprone position (typical for any ERCP procedure) renders the appearance of a venous air embolus more likely. Endoscopists should have an increased clinical suspicion of an air embolus in any ERCP patient that deteriorates abruptly upon position change at the end of the procedure $[59,63]$.

In the case of venous air embolism, the embolus travels from the superior vena cava to the right heart, leading to right ventricular strain and pulmonary hypertension, ending in cardiovascular collapse. In the case of systemic arterial air embolism, the embolus enters the aorta with the end result being myocardial ischemia, arrhythmias, congestive heart failure, cardiac arrest (in case of coronary emboli), or cerebral ischemia and increased intracranial pressure (in case of cerebral emboli). In the case of paradoxical air embolism, the venous embolus reaches the systemic circulation through, most commonly, an intracardiac shunt (patent foramen ovale), with the end result depending on the appearance of a cardiac or cerebral embolus. Other shunts implicated include (1) intrapulmonary right to left shunts, (2) arteriovenous shunts, (3) an atrial septal defect, (4) air passage into the left atrium via the pulmonary veins, (5) Thebesian veins, (6) insertion of the caval veins directly into the left atrium, and (7) retrograde flow into cerebral veins via the superior vena cava [59-61].

However, the absence of such an abnormality does not rule out paradoxical air embolism in patients undergoing ERCP, perhaps having to do with the fact that the differences in gases' partial pressures, bubble sizes, surface tensions, and vascular pressure influence emboli passage across the lungs $[14,41,44,46,60,64]$.

\section{Diagnosis}

Since early recognition increases the chances of patient survival, endoscopists should be highly motivated and trained to recognize this complication as early as possible, differentiating it from any sedation-related neurologic and/or cardiopulmonary problems due to central nervous system ischemia or hemorrhage. Since air may be rapidly absorbed from the circulation while diagnostic tests are being arranged, imaging or invasive procedures are sometimes inaccurate. Needless to say, all invasive diagnostic tests should be done after the patient's initial hemodynamic stabilization or while cardiopulmonary resuscitation takes place [59-62].

Possible clinician tools, studies, and their findings that can help diagnose air embolism during and after ERCP are summarized in Table 2.

\section{Karger'=}




\section{Case Reports in Gastroenterology}

\begin{tabular}{l|l}
\hline Case Rep Gastroenterol 2021;15:456-469 \\
\hline DOI: 10.1159/000514706 & $\begin{array}{l}\text { @ 2021 The Author(s). Published by S. Karger AG, Basel } \\
\text { www.karger.com/crg }\end{array}$ \\
\hline
\end{tabular}

Ekmektzoglou et al.: Paradoxical Air Embolism after ERCP

\section{Treatment}

Initial Measures

In any ERCP patient showing signs of rapid hemodynamic compromise raising the suspicion of air embolism, the first step requires terminating the procedure so as to prevent further gas entry; if possible, the endoscopist should opt for decompressing the upper gastrointestinal tract while withdrawing the side viewing endoscope (decompression via the nasogastric tube can follow at a later time).

Earlier reports advocated putting the patient in a Trendelenburg position to minimize cerebral air emboli. However, recent reports strongly object to this practice as it can increase intracranial pressure and worsen cerebral edema (in cerebral air embolism patients). In arterial air embolism, the supine decubitus position should be preferred. Overall, the left lateral decubitus position (Durant maneuver) is preferred. This helps to prevent air from traveling through the right side of the heart into the pulmonary arteries, leading to right ventricular outflow obstruction (air migrates superiorly into the right ventricular making it less likely to embolize as the right ventricular outflow tract is placed inferior to the right ventricular cavity) [65].

Hemodynamic and respiratory stabilization are the next steps. In cardiac arrest patients, cardiopulmonary resuscitation should start immediately. Cardiopulmonary resuscitation can, also, break large air bubbles into smaller ones and, through the increased intrathoracic pressure produced, can force air out of the right ventricular into the pulmonary vessels. The patient should be put on high flow $\mathrm{O}_{2}$ (beneficial for eliminating gas bubbles through a diffusion gradient as well as for treating hypoxia). If the patient was not intubated beforehand, in cardiac arrest patients or in patients exhibiting signs of cerebral hypoperfusion, an endotracheal tube should be secured as quickly as possible so as to protect the airway and provide adequate oxygenation [59].

Immediate volume expansion through fluid resuscitation is necessary so as to increase central venous pressure and thereby prevent further entry of gas into the venous circulation. Whether colloids or crystalloids should be administered remains a matter of debate. However, for cerebral air embolism patients with signs of increased intracranial pressure or cerebral edema, one must choose hyperosmolar solutions. Administration of vasotropes is essential for hemodynamically collapsed patients unresponsive to fluid resuscitation [60-62, 66, 67].

If bedside echocardiography confirms air in the right heart, a central venous catheter can be is inserted so as to evacuate up to $50 \%$ of entrained air, but also for central venous pressure monitoring $[61,68]$.

\section{Specific Treatment}

Isolated venous air embolism usually requires no specific treatment; arterial air embolism should be treated as if treating patients with decompression sickness - first-aid $\mathrm{O}_{2}$ followed by hyperbaric $\mathrm{O}_{2}$ [69]. Timely hyperbaric $\mathrm{O}_{2}$ therapy is the definitive treatment as it may decrease the size of air emboli by facilitating gas reabsorption, therefore minimizing air bubbles, reducing cerebral edema, reducing platelet aggregation due to bubble-induced endothelial damage, accelerating nitrogen reabsorption, preventing release of free $\mathrm{O}_{2}$ radicals, and

\section{Karger'=}




\section{Case Reports in Gastroenterology}

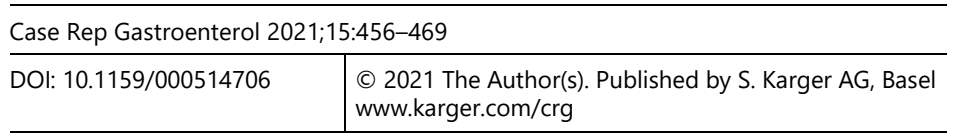

Ekmektzoglou et al.: Paradoxical Air Embolism after ERCP

increasing $\mathrm{O}_{2}$ concentrations in the blood (improving tissue oxygenation and reducing ischemic reperfusion injury). Timely hyperbaric $\mathrm{O}_{2}$ therapy administered within the first $5 \mathrm{~h}$ increases the chance for full recovery by $50 \%$ [70-72].

\section{Prophylaxis}

Since specific treatment modalities for air embolism are not always at hand, much interest has been drawn to recognize high-risk patients and implement specific prophylactic measures so as to reduce the severity (or even the incidence) of the disease.

Firstly, the importance of performing ERCPs only when clinically indicated cannot be overstated enough; by not overperforming ERCPs, the incidence of peri-ERCP adverse effects is kept to a minimum. Regarding patients per se, optimizing their volume status and maintaining normovolemia can prevent air embolism during the endoscopy [70].

Nowadays, $\mathrm{CO}_{2}$ has replaced air as the "gold standard" for distension in any gastrointestinal endoscopic procedure. $\mathrm{CO}_{2}$ markedly increases the safety margin of unintended gas migration into the circulation, even though $\mathrm{CO}_{2}$ embolization has also been reported [73-75]. As mentioned in earlier reports relating to air (and not $\mathrm{CO}_{2}$ ), reducing the maximum air pressure has also been found to decrease the risk of developing cerebral air embolism. Insufflated air and the rate of infusion are decisive for the outcome [76]. Some endoscopists favor water/ saline irrigation to distend the biliary tree when performing direct retrograde cholangioscopy [77].

Researchers advocate the use of bedside precordial Doppler ultrasound for quick air detection within the heart and pulmonary vasculature, even before clinical symptoms appear, although real-time clinical data are lacking [59]. Other go even further by suggesting the use of echocardiography to rule out the presence of right-to-left shunt in all patients scheduled for ERCP [58].

\section{Statement of Ethics}

We have not submitted an ethical institutional review board statement. The patient gave his written informed consent for publication of his case.

\section{Conflict of Interest Statement}

The authors have no conflicts of interest to declare.

\section{Funding Sources}

The authors declare that there are no funding sources.

\section{Karger'=}




\section{Case Reports in Gastroenterology}

Case Rep Gastroenterol 2021;15:456-469

DOI: $10.1159 / 000514706$

(C) 2021 The Author(s). Published by S. Karger AG, Basel www.karger.com/crg

Ekmektzoglou et al.: Paradoxical Air Embolism after ERCP

\section{Author Contributions}

K. Ekmektzoglou, G. Alexandrakis, and P. Apostolopoulos designed the study. K. Dimopoulos, P. Tsibouris, C. Kalantzis, and E. Vlachou collected the clinical data. K. Ekmektzoglou, G. Alexandrakis, and P. Apostolopoulos analyzed the data and wrote the manuscript.

\section{References}

1 Dumonceau JM, Tringali A, Papanikolaou IS, Blero D, Mangiavillano B, Schmidt A, et al. Endoscopic biliary stenting: indications, choice of stents, and results: European Society of Gastrointestinal Endoscopy (ESGE) Clinical Guideline - Updated October 2017. Endoscopy. 2018 Sep;50(9):910-30.

2 Chandrasekhara V, Khashab MA, Muthusamy VR, Acosta RD, Agrawal D, Bruining DH, et al.; ASGE Standards of Practice Committee. Adverse events associated with ERCP. Gastrointest Endosc. 2017 Jan;85(1):32-47.

3 Young Bang J, Cote GA. Rare and underappreciated complications of endoscopic retrograde cholangiopancreatography. Tech Gastrointest Endosc. 2014;16(4):195-201.

4 Afreen LK, Bryant AS, Nakayama T, Ness TJ, Jones KA, Morgan CJ, et al. Incidence of Venous Air Embolism During Endoscopic Retrograde Cholangiopancreatography. Anesth Analg. 2018 Aug;127(2):420-3.

5 Olaiya B, Adler DG. Air embolism secondary to endoscopy in hospitalized patients: results from the National Inpatient Sample (1998-2013). Ann Gastroenterol. 2019 Sep-Oct;32(5):476-81.

6 Ali Z, Bolster F, Goldberg E, Fowler D, Li L. Systemic air embolism complicating upper gastrointestinal endoscopy: a case report with post-mortem CT scan findings and review of literature. Forensic Sci Res. 2017 Jan;1(1):52-7.

7 Argüelles García B, García Blanco A, Meilán Martínez A, Calvo Blanco J. Cerebral artery air embolism secondary to endoscopic retrograde cholangiopancreatography. Gastroenterol Hepatol. 2009 Nov;32(9): 614-7.

8 Arora A, Mukund A, Garg H, Patıdar Y. Portal venous air embolization. Turk J Gastroenterol. 2013;24(4):3745.

9 Athauda D, Tan GS, De Pablo-Fernandez E. Cerebral air embolism during endoscopic retrograde cholangiopancreatography: treatment with therapeutic hypothermia. Endoscopy. 2014;46(Suppl 1): UCTN:E151-2.

10 Barbeiro S, Atalaia-Martins C, Gonçalves C, Cotrim I. Portal air embolism after endoscopic retrograde cholangiopancreatography. Rev Esp Enferm Dig. 2017 Jun;109(6):452-3.

11 Barthet M, Membrini P, Bernard JP, Sahel J. Hepatic portal venous gas after endoscopic biliary sphincterotomy. Gastrointest Endosc. 1994 Mar-Apr;40(2 Pt 1):261-3.

12 Bastovansky A, Stöllberger C, Finsterer J. Fatal Cerebral Air Embolism Due to a Patent Foramen Ovale during Endoscopic Retrograde Cholangiopancreatography. Clin Endosc. 2014 May;47(3):275-80.

13 Bechi A, Nucera MP, Olivotto I, Manetti R, Fabbri LP. Complete neurological recovery after systemic air embolism during endoscopic retrograde cholangiopancreatography. Minerva Anestesiol. 2012 May;78(5): 622-5.

14 Bisceglia M, Simeone A, Forlano R, Andriulli A, Pilotto A. Fatal systemic venous air embolism during endoscopic retrograde cholangiopancreatography. Adv Anat Pathol. 2009 Jul;16(4):255-62.

15 Blind PJ, Oberg L, Hedberg B. Hepatic portal vein gas following endoscopic retrograde cholangiography with sphincterotomy. Case report. Eur J Surg. 1991 Apr;157(4):299-300.

16 Cha ST, Kwon CI, Seon HG, Ko KH, Hong SP, Hwang SG, et al. Fatal biliary-systemic air embolism during endoscopic retrograde cholangiopancreatography: a case with multifocal liver abscesses and choledochoduodenostomy. Yonsei Med J. 2010 Mar;51(2):287-90.

17 Chavalitdhamrong D, Draganov PV. Acute stroke due to air embolism complicating ERCP. Endoscopy. 2013;45(Suppl 2):UCTN:E177-8.

18 Cooper JS, Thomas J, Singh S, Brakke T. Endoscopic Bubble Trouble: Hyperbaric Oxygen Therapy for Cerebral Gas Embolism During Upper Endoscopy. J Clin Gastroenterol. 2017 Jul;51(6):e48-51.

19 Di Pisa M, Chiaramonte G, Arcadipane A, Burgio G, Traina M. Air embolism during endoscopic retrograde cholangiopancreatography in a pediatric patient. Minerva Anestesiol. 2011 Jan;77(1):90-2. 


\section{Case Reports in Gastroenterology}

Ekmektzoglou et al.: Paradoxical Air Embolism after ERCP

20 Dioscoridi L, Roselli E, Melis V, Mutignani M. Air embolism of right coronary artery after ERCP. BMJ Case Rep. 2020 Jun;13(6):e236135.

21 Duburque C, Beaujard E, Landel JB, Rihani R, Merouani K, Yassine W, et al. Life-threatening air embolism during ERCP. Endoscopy. 2014;46(Suppl 1):UCTN:E250-1.

22 Efthymiou M, Raftopoulos S, Antonio Chirinos J, May GR. Air embolism complicated by left hemiparesis after direct cholangioscopy with an intraductal balloon anchoring system. Gastrointest Endosc. 2012 Jan;75(1): 221-3.

23 Fernandez-Fernandez J, Real-Noval H, Rodriguez-Rodriguez E. Massive cerebral air embolism following endoscopic retrograde cholangiopancreatography. A case report and review of the literature. Rev Neurol. 2016 Dec;63(11):497-500. Spanish.

24 Giuly E, Pesenti C, Pernoud N, Bories E, Francon D. Air embolism: an unusual complication of endoscopic retrograde cholangiopancreatography. Ann Fr Anesth Reanim. 2005 Nov-Dec;24(11-12):1400-3. French.

25 Goins KM, May JM, Hucklenbruch C, Littlewood KE, Groves DS. Unexpected cardiovascular collapse from massive air embolism during endoscopic retrograde cholangiopancreatography. Acta Anaesthesiol Scand. 2010 Mar;54(3):385-8.

26 Hann A, Zizer E, Egger K, Allescher HD, Meining A. Fatal outcome due to CO2 emboli during direct cholangioscopy. Gut. 2018 Aug;67(8):1378-9.

27 Hauser G, Milosevic M, Zelić M, Stimac D. Sudden death after endoscopic retrograde cholangiopancreatography (ERCP) - case report and literature review. Medicine (Baltimore). 2014 Dec;93(27):e235.

28 Herman JB, Levine MS, Long WB. Portal venous gas as a complication of ERCP and endoscopic sphincterotomy. Am J Gastroenterol. 1995 May;90(5):828-9.

29 Jivcu C, Luedy H, Raschke R. Questioning the incidence of air emboli following endoscopic retrograde cholangiopancreatography. Am J Respir Crit Care Med. 2012;185:A5975.

30 Jow AZ, Wan D. Complication of cardiac air embolism during ERCP and EUS-assisted cyst-gastrostomy for pancreatic pseudocyst. Gastrointest Endosc. 2012 Jan;75(1):220-1.

31 Kalaitzakis E, Stern N, Sturgess R. Portal vein cannulation: an uncommon complication of endoscopic retrograde cholangiopancreatography. World J Gastroenterol. 2011 Dec;17(46):5131-2.

32 Kennedy C, Larvin M, Linsell J. Fatal hepatic air embolism following ERCP. Gastrointest Endosc. 1997 Feb; 45(2):187-8.

33 Kondo H, Naitoh I, Nakazawa T, Hayashi K, Nishi Y, Umemura S, et al. Development of fatal systemic gas embolism during direct peroral cholangioscopy under carbon dioxide insufflation. Endoscopy. 2016; 48(Suppl 1):E215-6.

34 Maccarone G, Shakoor T, Ellis B. Air embolism after percutaneous transhepatic biliary drainage and subsequent endoscopic retrograde cholangiopancreatography (ERCP). Endoscopy. 2011;43(Suppl 2): UCTN:E399.

35 Maggino L, Crinò SF, Bernardoni L, Marchegiani G, Malleo G, Salvia R, et al. An unforeseeable adverse event during ERCP. Endoscopy. 2016;48(Suppl 1):E278-9.

36 Mal F, Choury AD, De Castro V, Christidis C, Carbognani D, Validire P, et al. Fatal venous air embolism during biliary endoscopy. Gastroenterol Clin Biol. 2010 Apr-May;34(4-5):e17-8. French.

37 Marchesi M, Battistini A, Pellegrinelli M, Gentile G, Zoja R. Fatal air embolism during endoscopic retrograde cholangiopancreatography (ERCP): An "impossible" diagnosis for the forensic pathologist. Med Sci Law. 2016 Jan;56(1):70-3.

38 Markin NW, Montzingo CR. Paradoxical air embolus during end oscopic retrograde cholangiopancreatography: an uncommon fatal complication. A A Case Rep. 2015 Apr;4(7):87-90.

39 Mathew J Jr, Parker C 3rd, Wang J. Pulseless electrical activity arrest due to air embolism during endoscopic retrograde cholangiopancreatography: a case report and review of the literature. BMJ Open Gastroenterol. 2015 Jun;2(1):e000046.

40 Merine D, Fishman EK. Uncomplicated portal venous gas associated with duodenal perforation following ERCP: CT features. J Comput Assist Tomogr. 1989 Jan-Feb;13(1):138-9.

41 Mohammedi I, Ber C, Peguet O, Ould-Aoudia T, Duperret S, Petit P. Cardiac air embolism after endoscopic retrograde cholangiopancreatography in a patient with blunt hepatic trauma. J Trauma. 2002 Dec;53(6): 1170-2.

42 Nayagam J, Ho KM, Liang J. Fatal systemic air embolism during endoscopic retrograde cholangiopancreatography. Anaesth Intensive Care. 2004 Apr;32(2):260-4. 


\section{Case Reports in Gastroenterology}

Case Rep Gastroenterol 2021:15:456-469

DOI: $10.1159 / 000514706$

(C) 2021 The Author(s). Published by S. Karger AG, Basel www.karger.com/crg

Ekmektzoglou et al.: Paradoxical Air Embolism after ERCP

43 Nern C, Bellut D, Husain N, Pangalu A, Schwarz U, Valavanis A. Fatal cerebral venous air embolism during endoscopic retrograde cholangiopancreatography-case report and review of the literature. Clin Neuroradiol. 2012 Dec;22(4):371-4.

44 Rabe C, Balta Z, Wüllner U, Heller J, Hammerstingl C, Tiemann K, et al. Biliary metal stents and air embolism: a note of caution. Endoscopy. 2006 Jun;38(6):648-50.

45 Rangappa P, Uhde B, Byard RW, Wurm A, Thomas PD. Fatal cerebral arterial gas embolism after endoscopic retrograde cholangiopancreatography. Indian J Crit Care Med. 2009 Apr-Jun;13(2):108-12.

46 Romberg C. Systemic air embolism after ERCP: a case report and review of the literature (with video). Gastrointest Endosc. 2009 Nov;70(5):1043-5.

47 Painter NP, Kumar PA, Arora H. Acute pulmonary embolism during an endoscopic retrograde cholangiopancreatography. Ann Card Anaesth. 2014 Apr-Jun;17(2):145-7.

48 Park S, Ahn JY, Ahn YE, Jeon SB, Lee SS, Jung HY, et al. Two Cases of Cerebral Air Embolism That Occurred during Esophageal Ballooning and Endoscopic Retrograde Cholangiopancreatography. Clin Endosc. 2016 Mar;49(2):191-6.

49 Siddiqui J, Jaffe PE, Aziz K, Forouhar F, Sheppard R, Covault J, et al. Fatal air and bile embolism after percutaneous liver biopsy and ERCP. Gastrointest Endosc. 2005 Jan;61(1):153-7.

50 Simmons TC. Hepatic portal venous gas due to endoscopic sphincterotomy. Am J Gastroenterol. 1988 Mar; 83(3):326-8.

51 Sisk JM, Choi MD, Casabianca AB, Hassan AM. Two Cardiac Arrests Because of Venous Air Embolism During Endoscopic Retrograde Cholangiopancreatography: A Case Report. A A Case Rep. 2017 Feb;8(3):47-50.

52 Stabile L, Cigada M, Stillittano D, Morandi E, Zaffroni M, Rossi G, et al. Fatal cerebral air embolism after endoscopic retrograde cholangiopancreatography. Acta Anaesthesiol Scand. 2006 May;50(5):648-9.

53 Trabanco S, Pardo S, Williams M, Diaz J, Ruiz C. Cerebral air embolism after ERCP. J Clin Anesth. 2017 Feb; 36:133-5.

54 Vachalová I, Ernst S, Vynogradova I, Wöhrmann S, Heckmann JG. Cerebral air embolism via port catheter and endoscopic retrograde cholangio-pancreatography. Springerplus. 2013 Sep;2(1):477.

55 Tan BK, Saunier CF, Cotton F, Gueugniaud PY, Piriou V. Thoracoabdominal CT scan: a useful tool for the diagnosis of air embolism during an endoscopic retrograde cholangiopancreatography. Ann Fr Anesth Reanim. 2008 Mar;27(3):240-3. French.

56 van Boxel GI, Hommers CE, Dash I, Goodman AJ, Green J, Orme RM. Myocardial and cerebral infarction due to massive air embolism following endoscopic retrograde cholangiopancreatography (ERCP). Endoscopy. 2010;42(Suppl 2):E80-1.

57 Voiosu TA, Gheorghe AV, Lepădat G, Mateescu RB, Rimbaș M. Transient venous air embolism after ERCP: worrisome or not? J Ultrason. 2020;20(80):e67-9.

58 Wills-Sanin B, Cárdenas YR, Polanco L, Rivero O, Suarez S, Buitrago AF. Air embolism after endoscopic retrograde cholangiopancreatography in a patient with Budd Chiari syndrome. Case Rep Crit Care. 2014; 2014:205081.

59 Donepudi S, Chavalitdhamrong D, Pu L, Draganov PV. Air embolism complicating gastrointestinal endoscopy: A systematic review. World J Gastrointest Endosc. 2013 Aug;5(8):359-65.

60 Maqsood MH, Mirza N, Hanif MA, Hanif H, Saleem M, Maqsood MA, et al. Clinical Presentation, Diagnosis, and Management of Air Embolism During Endoscopic Retrograde Cholangiopancreatography. Gastroenterol Res. 2019 Dec;12(6):283-7.

61 Lanke G, Adler DG. Gas embolism during endoscopic retrograde cholangiopancreatography: diagnosis and management. Ann Gastroenterol. 2019 Mar-Apr;32(2):156-67.

62 Finsterer J, Stöllberger C, Bastovansky A. Cardiac and cerebral air embolism from endoscopic retrograde cholangio-pancreatography. Eur J Gastroenterol Hepatol. 2010 Oct;22(10):1157-62.

63 Prielipp RC, Brull SJ. Vascular Air Embolism and Endoscopy: Every Bubble Matters. Anesth Analg. 2018 Aug; 127(2):333-5.

64 Gottdiener JS, Papademetriou V, Notargiacomo A, Park WY, Cutler DJ. Incidence and cardiac effects of systemic venous air embolism. Echocardiographic evidence of arterial embolization via noncardiac shunt. Arch Intern Med. 1988 Apr;148(4):795-800.

65 Cooper J. Treatment of Endoscopy Associated Cerebral Gas Embolism. Am J Gastroenterol. 2018 Dec; 113(12):1742-4.

66 Visvanathan A, Dennis M, Whiteley W. Parenteral fluid regimens for improving functional outcome in people with acute stroke. Cochrane Database Syst Rev. 2015 Sep;9(9):CD011138.

67 Ropper AH. Hyperosmolar therapy for raised intracranial pressure. N Engl J Med. 2012 Aug;367(8):746-52. 


\section{Case Reports in Gastroenterology}

\begin{tabular}{l|l}
\hline Case Rep Gastroenterol 2021;15:456-469 \\
\hline DOI: 10.1159/000514706 & $\begin{array}{l}\text { (C) 2021 The Author(s). Published by S. Karger AG, Basel } \\
\text { www.karger.com/crg }\end{array}$ \\
\hline
\end{tabular}

Ekmektzoglou et al.: Paradoxical Air Embolism after ERCP

68 McCarthy CJ, Behravesh S, Naidu SG, Oklu R. Air Embolism: Practical Tips for Prevention and Treatment. J Clin Med. 2016 Oct;5(11):93.

69 Moon RE. Hyperbaric treatment of air or gas embolism: current recommendations. Undersea Hyperb Med. 2019 Sep-Dec;46(5):673-83.

70 Ghannam M, Beran A, Ghazaleh D, Ferderer T, Berry B, Banna MA, et al. Cerebral Air Embolism after Esophagogastroduodenoscopy: Insight on Pathophysiology, Epidemiology, Prevention and Treatment. J Stroke Cerebrovasc Dis. 2019 Dec;28(12):104403.

71 Malik N, Claus PL, Illman JE, Kligerman SJ, Moynagh MR, Levin DL, et al. Air embolism: diagnosis and management. Future Cardiol. 2017 Jul;13(4):365-78.

72 Murphy BP, Harford FJ, Cramer FS. Cerebral air embolism resulting from invasive medical procedures. Treatment with hyperbaric oxygen. Ann Surg. 1985 Feb;201(2):242-5.

73 Wang WL, Wu ZH, Sun Q, Wei JF, Chen XF, Zhou DK, et al. Meta-analysis: the use of carbon dioxide insufflation vs. room air insufflation for gastrointestinal endoscopy. Aliment Pharmacol Ther. 2012 May;35(10):1145-54.

74 Dellon ES, Hawk JS, Grimm IS, Shaheen NJ. The use of carbon dioxide for insufflation during GI endoscopy: a systematic review. Gastrointest Endosc. 2009 Apr;69(4):843-9.

75 Seifert H, Biermer M, Schmitt W, Jürgensen C, Will U, Gerlach R, et al. Transluminal endoscopic necrosectomy after acute pancreatitis: a multicentre study with long-term follow-up (the GEPARD Study). Gut. 2009 Sep; 58(9):1260-6.

76 Katzgraber F, Glenewinkel F, Fischler S, Rittner C. Mechanism of fatal air embolism after gastrointestinal endoscopy. Int J Legal Med. 1998;111(3):154-6.

77 Farnik H, Weigt J, Malfertheiner P, Grützmann A, Gossner L, Friedrich-Rust M, et al. A multicenter study on the role of direct retrograde cholangioscopy in patients with inconclusive endoscopic retrograde cholangiography. Endoscopy. 2014 Jan;46(1):16-21. 
Case Reports in
Gastroenterology

Case Rep Gastroenterol 2021;15:456-469

466

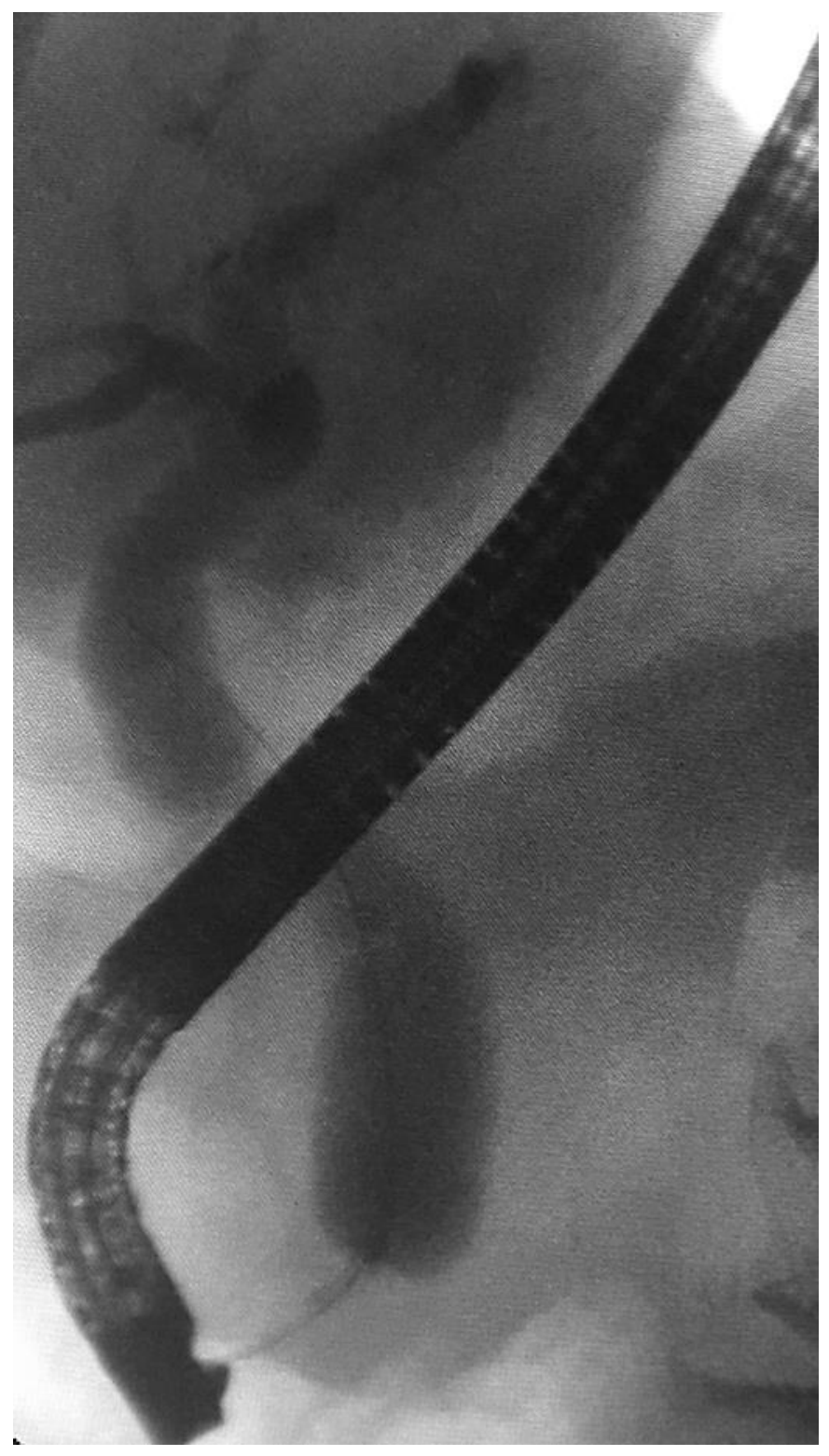

Fig. 1. Endoscopic retrograde cholangiopancreatography cholangiogram revealing a 10-mm mid-common bile duct stricture with concomitant intrahepatic duct and suprapapillary dilation; no filling defect was noted.

\section{Karger's}




\section{Case Reports in Gastroenterology}

Case Rep Gastroenterol 2021;15:456-469
(C) 2021 The Author(s). Published by S. Karger AG, Basel www.karger.com/crg

Ekmektzoglou et al.: Paradoxical Air Embolism after ERCP
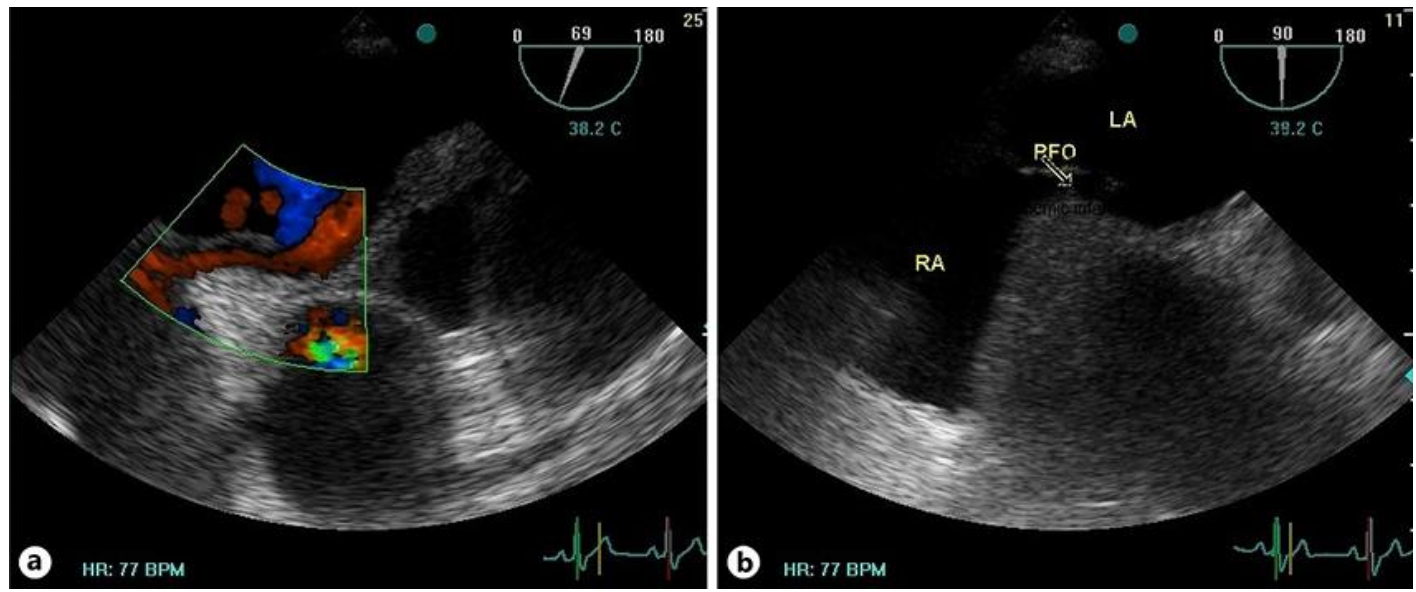

Fig. 2. a Transesophageal color Doppler showing the interatrial shunt due to the presence of patent foramen ovale. $\mathbf{b}$ Transesophageal bubble study confirming the interatrial shunt due to the presence of patent foramen ovale.

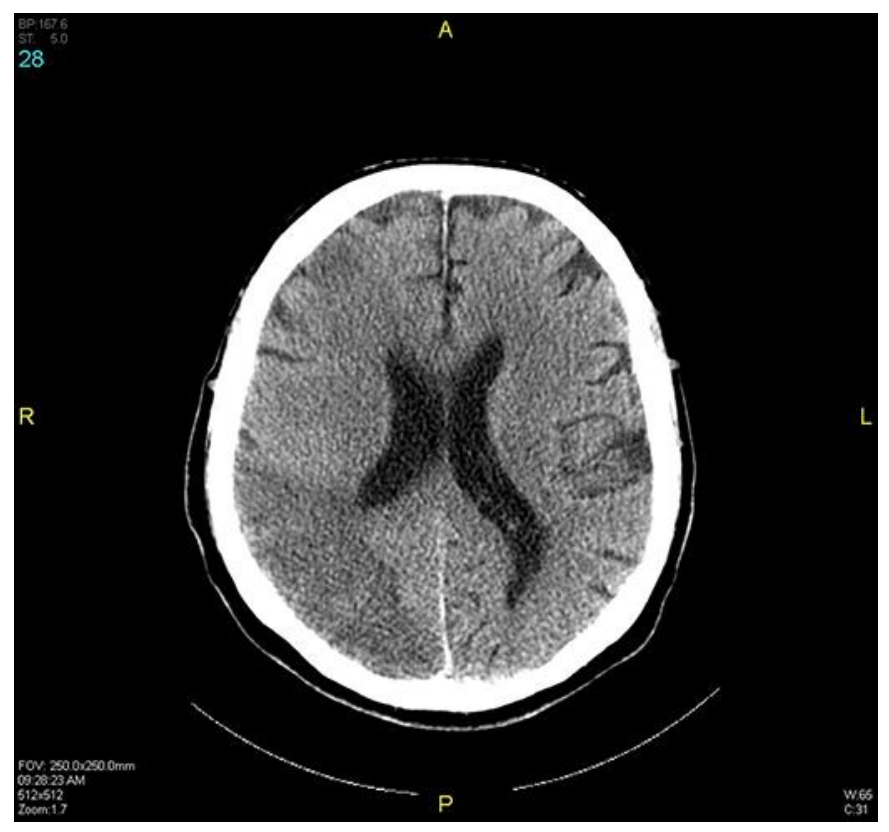

Fig. 3. Head computed tomography revealing an extensive hypodense lesion in the right parieto-occipital lobe, indicative of an extensive ischemic infarction. 


\section{Case Reports in Gastroenterology}

Table 1. Risk factors for developing air embolism (not only for endoscopic retrograde cholangiopancreatography patients)

Previous interventions/surgeries

Percutaneous transhepatic biliary drainage

Sphincterotomy

Stent insertion

Endoscopic papillary balloon dilation

Pre-cut papillotomy

Choledochoduodenostomy

Choledochojejunostomy

Hepaticojejunostomy

Status post Whipple's operation

Billroth II

Roux-en-Y

Kasai procedure (hepatoportoenterostomy)

Cholangioscopy

Insufflation of air with high pressure

Transhepatic portosystemic shunts/cholangiopathy

Bilio-venous fistula

Bilio-duodenal fistula

Portal cavernoma/splenomes-enteric portal shunt

Choledochal varices

Extrahepatic portal vein obstruction/Budd-Chiari syndrome

Splenomesenteric portal shunt

Blunt/penetrating liver trauma

Bile duct/surrounding veins inflammation

Cholangitis

Pylephlebitis

Biliary atresia

Gastrointestinal tumors

Gallbladder carcinoma

Cholangiocarcinoma

Hepatocellular carcinoma

Hepatic abscesses

Liver biopsy

Alcoholic liver cirrhosis

Transjugular intrahepatic portosystemic shunt

Recurrent/chronic pancreatitis

Mesenteric ischemia

Necrotizing enterocolitis

Gastric ulcer

Inflammatory bowel disease

Pneumatosis cystoides intestinalis 


\section{Case Reports in Gastroenterology}

\begin{tabular}{l|l} 
Case Rep Gastroenterol 2021;15:456-469 \\
\hline DOI: 10.1159/000514706 & $\begin{array}{l}\text { @ 2021 The Author(s). Published by S. Karger AG, Basel } \\
\text { www.karger.com/crg }\end{array}$ \\
\hline
\end{tabular}

Ekmektzoglou et al.: Paradoxical Air Embolism after ERCP

Table 2. Possible clinician tools, studies, and their findings that can help diagnose air embolism during and after endoscopic retrograde cholangiopancreatography

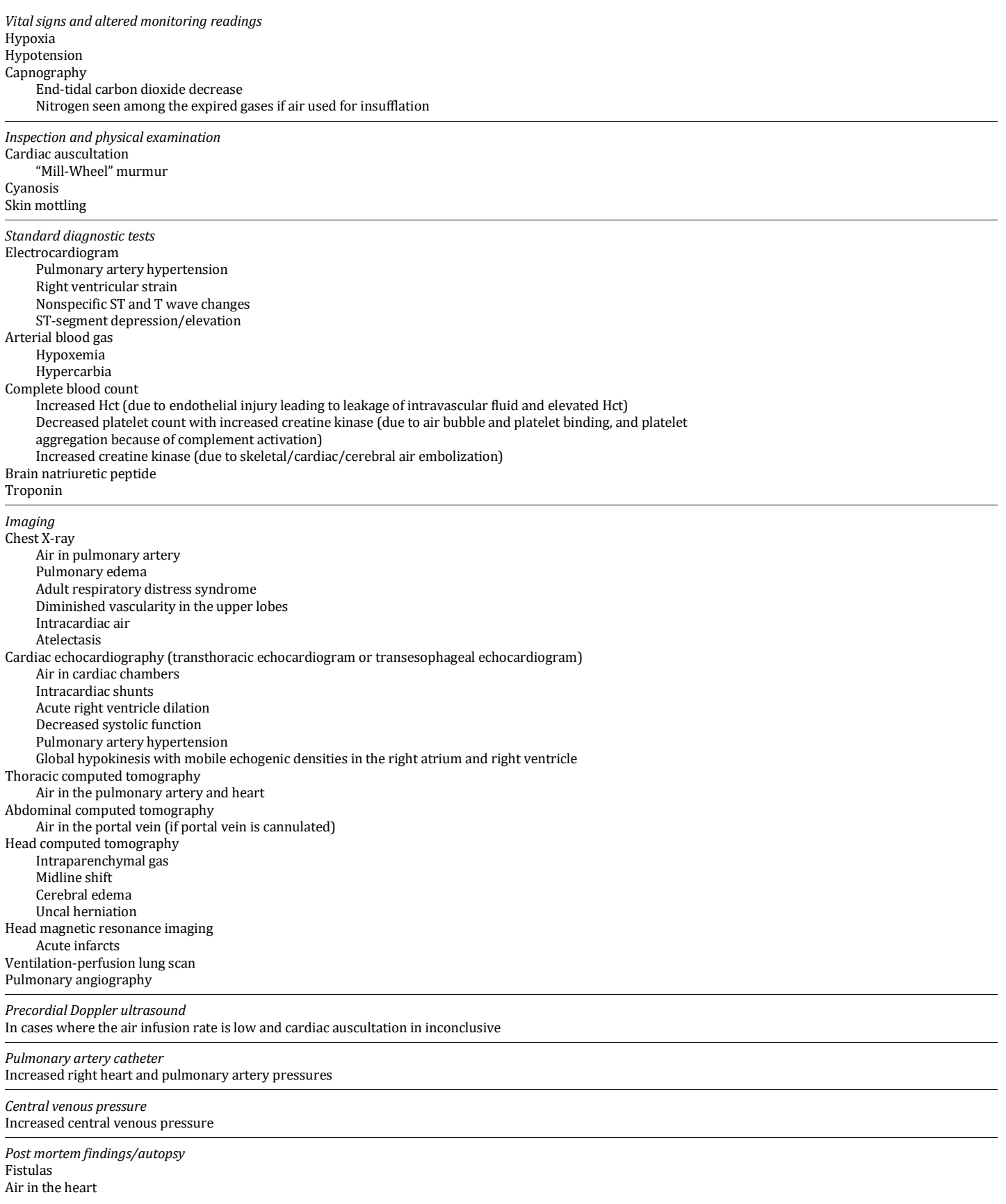

